\title{
Quality evaluation of clinical records of a group of general dental practitioners entering a quality assurance programme
}

\author{
R. G. Morgan, '
}

This paper discusses the importance of maintaining high quality clinical records. Evidence from studies carried out in the USA, Australia and Scandinavia shows that record keeping often falls well below accepted standards. Evidence of current standards in the UK, however, has tended to be anecdotal or circumstantial. An assessment was carried out on $\mathbf{4 7}$ general practitioners entering the quality assurance programme of a private capitation scheme. A sample of clinical records from each practitioner was analysed, and the presence or absence of key diagnostic and treatment planning entries were recorded. Overall, the quality of record keeping was poor, and in line with the findings of the other worldwide studies. Fundamental clinical entries that could impact on basic dental care provision were missing from many records. The frequency of recording for patients whose treatment was funded under NHS regulations was significantly worse than for patients whose treatment was privately funded.

\begin{abstract}
All dentists have a responsibility to A maintain clinical records, clearly stated by the GDC, ${ }^{1}$ and reinforced by bodies such as the $\mathrm{BDA}^{2}$ and GDPA. ${ }^{3}$

Clinical records are fundamental to the process of the delivery of dental care, contributing to the diagnosis, planning and correct sequencing of treatment. They need to be legible, accurate, comprehensive and contemporaneous. ${ }^{4}$ They should provide a clear and accurate picture of the progress of oral disease, and of the care and treatment given to a patient. Their primary function is communication: from practitioner to colleague, practitioner to or from another healthcare professional, and practitioner to himself. ${ }^{5}$
\end{abstract}

$\overline{1^{*} \text { Clinical Lecturer, University of Birmingham School }}$ of Dentistry, St Chad's Queensway, Birmingham B4 6 NN

${ }^{*}$ Correspondence to: Robert Morgan

email:r.g.morgan@bham.ac.uk

REFEREED PAPER

Received 15.11.00; Accepted 02.04.01

(C) British Dental Journal 2001; 191: 436-441
In brief

- The importance of clinical record keeping is discussed

- There is at present little reliable evidence of standards of record keeping in general dental practice in the UK

- This study shows a widespread failure to record even basic clinical findings

In addition to their contribution to patient care, clinical records also fulfil medicolegal, administrative and financial functions within general practice. They have also become essential tools for clinical audit and quality assurance. ${ }^{6}$ In the UK, however, this readily available source of information has generally not been used for quality assurance (QA) purposes.

Although good records do not ensure the adequacy of dental care, they do provide an opportunity to evaluate it, which poor records do not. ${ }^{6}$ Therefore, in order for a QA programme to be fully effective, the clinical records must be maintained at a level that allows proper assessment of the care provided.

The current guidance for general dental practice, issued by the Faculty of General Dental Practitioners (UK) includes guidelines on the contents of clinical records. ${ }^{4}$ Items that should be recorded are listed in Table 1.

A number of private capitation plans have developed in the UK over the past decade, as an alternative to NHS funding of dental care. These schemes have, to varying extents and at varying times during their development, sought to introduce QA to the dental care provided by their dentists. ${ }^{7,8}$ These QA programmes have been developed with the intention of improving and maintaining the quality of treatment provision, helping practitioners to ensure that their practices are performing to current standards and providing reassurance to the subscribing patient that they are receiving high quality care. Programmes of this type are usually based on assessment of the structure and process of care provided. A comprehensive QA system is designed to cover all the aspects of patient evaluation, diagnosis, treatment planning and treatment, and the environment in which this is carried out, that may have an impact on the outcome of patient care. Evaluation of the patient record invariably forms a major part of these programmes.

The aim of this study was to evaluate the quality of clinical records of a group of dentists who were intending to provide treatment to patients under a private capitation scheme. The quality assessment formed the initial step in a larger, and continuing, QA programme.

\section{Study outline}

Forty-seven general dental practitioners in England and Wales being assessed by the quality assurance programme of BUPA 


\section{Table I Required entries in patients' records}

- Patient's personal details, to include name, address, date of birth, gender and contact telephone number

- Medical and dental history, to include alerts, precautions, current treatment and general medical practitioner information. This should be regularly updated

- Examination of the dentofacial area and oral mucosa, including cancer screening

- An initial dental examination, including periodontal status, restorations, caries, appliances, basic occlusion and any necessary radiographs, with a written report

- Sequenced treatment plan, together with any changes

- Signed and dated notes at each visit, to include details of treatment, drugs administered and prescribed (including local anaesthetic) and advice given

- A valid consent process, at whatever level required

- Any treatment declined by the patient should be recorded

- Additionally, a procedure for the archiving and storage of non-active patient records should be present

- Practices using computers for any part of the records must be registered with the data protection registrar

DentalCover were used in the study. These represented a sample of the practitioners visited by one assessor during the period June 1998 to June 1999, and who consented to take part in the study. The practitioners were initially selected for assessment by administrative staff on the basis of availability. The dentists sampled in this study were therefore not randomly drawn from the total population of general practitioners in England and Wales.

Full details of the expected criteria for record keeping, along with health and safety, infection control and administrative standards ${ }^{7}$ were made available to all participating practitioners when they joined the scheme. An initial practice quality assessment was the first point of an audit cycle that formed a fundamental part of the QA programme. The dentists sampled in this study, therefore, were aware in advance that an assessment would take place, and aware that clinical records would be examined, although the exact standards that applied to the assessment criteria had not been specified. In view of this it could be concluded that the findings of this study, based on a group of dentists voluntarily involved in a QA programme, represent the best-case scenario of clinical record keeping in England and Wales.

Prior to the practice visit, the assessor was supplied with a list of patients treated by the practitioner under the capitation scheme. A sample of 10 patients was obtained by selecting every $n / 10$ patient on the list (where $n$ represented the total number of patients). If the selected patient was edentulous, was a young adult with remaining deciduous teeth, or if the record was unavailable, then the next patient on the list was selected. This systematic sampling method, although convenient, could have introduced bias into the selection of the study sample.

The clinical records were examined, and the presence or absence of clinical details was noted. The records were examined at the point at which the patient began treatment under the capitation scheme. The criteria were evaluated against the minimum standards adopted by BUPA DentalCover, listed in Table 2. Record entries that were unclear or difficult to read were biased toward the practitioner unless obviously inappropriate.

The source of treatment funding in place before the patient began treatment under the capitation scheme was recorded. All the dentists in the sample provided treatment under NHS contract and private contract, although the proportion of patients who had received treatment under each payment system was not recorded. The number of years since initial registration with the GDC was noted, as was the gender of the dentist.

Statistical analysis of the results was carried out using $\chi^{2}$ tests on pairs of variables, using 1 degree of freedom. Values of $P<0.05$ were considered to be significant

\section{Results}

A total of 470 clinical records were examined. The findings recorded for six clinical records were illegible or were not complete and have not been included in the results, leaving a sample of 464 for analysis. It must be admitted that this finding, in a study of the quality of record keeping, contains more than a touch of irony.

The frequency with which each expected record notation appeared is shown in Figure 1. Overall, the most frequently recorded item was the full tooth charting, completed in $325(70 \%)$ records. Completed medical histories were present in 207 (44.6\%) cases, and soft tissue findings in 93 (20\%).

Periodontal screening had been recorded in $96(20.7 \%)$ cases, and the screening revealed $16(3.4 \%)$ patients with moderate to severe disease (BPE codes 3 or 4 , or equivalent). Some form of pocket charting for 


\section{Record component}

Medical history

Examination of soft issues

Full tooth charting

Periodontal screening

Periodontal examination

Diagnosis

Treatment plan

\section{Standard}

An initial written questionnaire completed and signed. Updated regularly, with updates dated and recorded

Examination of the soft tissues forming part of normal examination protocol, findings recorded within the past year

Charting of the teeth, restorations, prostheses and caries present, recorded within the last 5 years

Periodontal screening (BPE or equivalent) routinely monitored and recorded at least annually

At risk patients identified from periodontal screening. Appropriate pocket depth recordings within the past 5 years

Any notation within the past 2 years that could be used to identify the current level of dental disease

Any notation within the past 2 years that could be used to plan anticipated treatment (rather than having to deduce the treatment plan retrospectively from the treatment provided) periodontally compromised patients was found in $7(1.5 \%)$ cases. Although it is impossible to know the periodontal status of all the patients, as nearly $80 \%$ of them had no periodontal monitoring at all, $16.6 \%$ of those patients who had been screened had moderate to severe periodontal disease. Of those patients who had been identified as having a high-risk of periodontal disease, $43.8 \%$ had a full pocket depth chart recorded within the past 5 years.

Despite the very broad standard considered as acceptable for diagnosis and treatment planning, it is disappointing that these items were present in only $45(9.7 \%)$ and 79 (17\%) respectively of the records examined.

Male dentists comprised $34(72 \%)$ of the sample, with 13 (28\%) female. Thirty-three $(70 \%)$ of the dentists sampled had been qualified more than 15 years, with 14 (30\%) less than 15 years. Two hundred and eighty two $(60.8 \%)$ patients had been treated under contract to the NHS, $182(39.2 \%)$ had been treated under private contract.

Table 3 shows the distribution of assessment findings between the dentists with

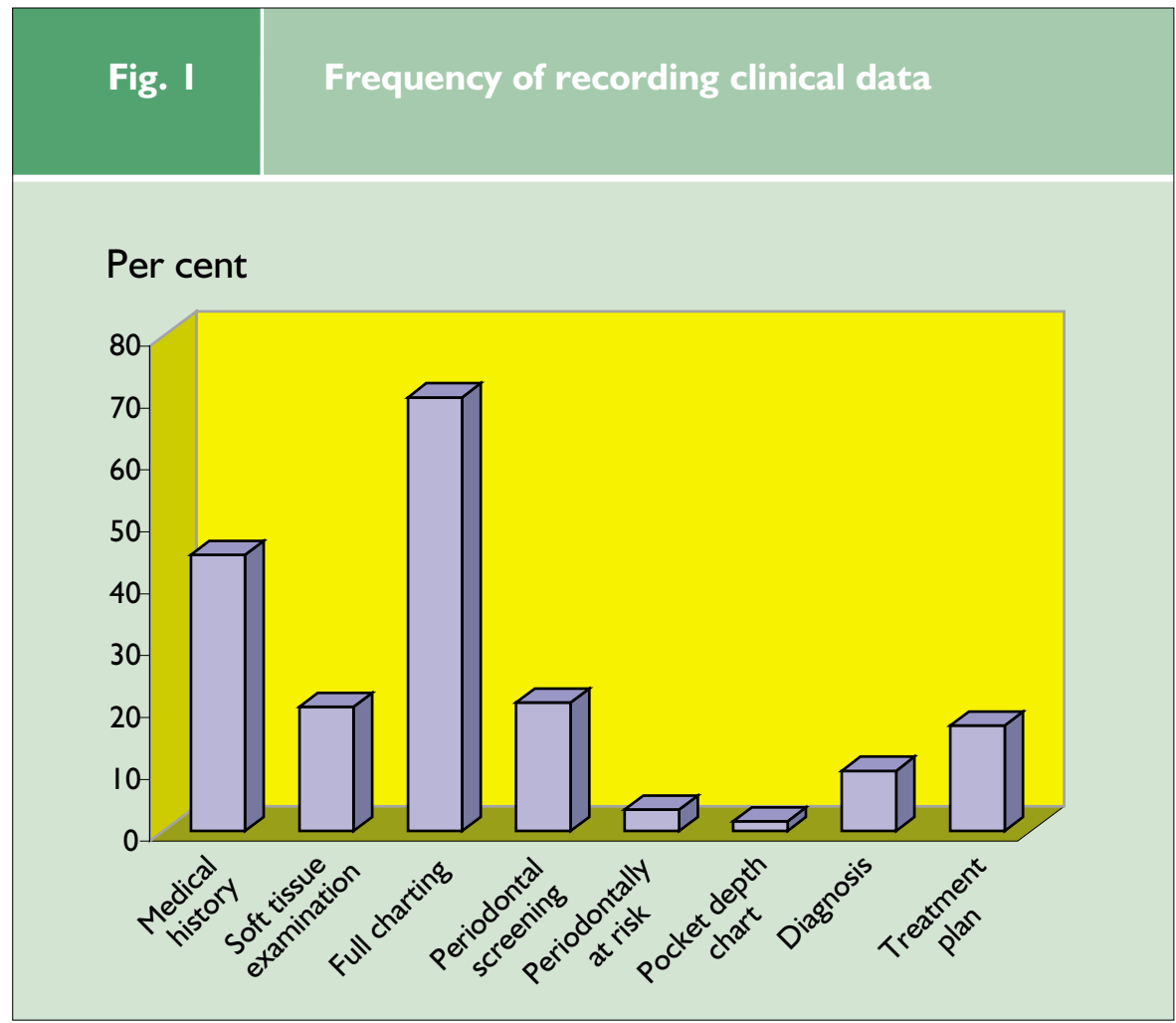


more than 15 years' experience and those with less than 15 years; between dentists according to gender; and between patient records according to method of payment. No significant differences, apart from the recording of soft tissue examinations, were found between treatment notations recorded by male and female dentists. Dentists with more than 15 years' postqualification experience tended to record significantly more medical histories, soft tissue examinations, periodontal screenings and treatment plans $(0.05>P>0.01)$ than did dentists qualified for less than 15 years. The frequency of recording of all the assessed criteria in the clinical records of patients whose care was privately funded was significantly greater than those whose funding was through the NHS $(P<0.01)$. These differences are shown in Figure 2

\section{Discussion}

Little direct information on the standards of clinical record keeping has been published in the UK. Reports and observations from mass disasters, where identification of bodies is often only possible by dental means, have previously highlighted deficient or incorrect records. ${ }^{9,10}$ Submissions for prior approval of treatment have shown fundamental errors in, and the absence of, straightforward dental chartings. ${ }^{11}$ An analysis of medicolegal cases involving infective endocarditis found poor quality medical histories and inadequate record keeping in many of the incidents. ${ }^{12}$ Marshall refined a quality assessment instrument for assessing standards in general dental practice that found differentials in many aspects of NHS, mixed and private practice, including standards of record keeping. ${ }^{13}$

The lack of more general information about the quality of clinical records may be because of the nature of general dental practice in the UK. Most practitioners are independent contractors, providing services through the National Health Service Regulations, or private contract. The autonomy of this situation gives little opportunity for an overview of treatment provision. Although the dental practice boards have the right to access NHS records, informa- tion gained has not been collated and made available for publication. Practitioners applying for positions as vocational trainers have practice inspections, involving a review of clinical records and radiographs. These inspections are organised on a regional basis, and no central collation of data is made. On a local level, health authorities carry out inspections of general practices, but these are of usually a structural audit format, and do not involve examination of patient records. With this background, the development of private capitation schemes, involving a wide crosssection of general practitioners, provides a unique access to clinical treatment provided in general dental practice.

The generally low level of notation in clinical records is mirrored in other parts of the world, where more formal investigations have been performed. Published studies

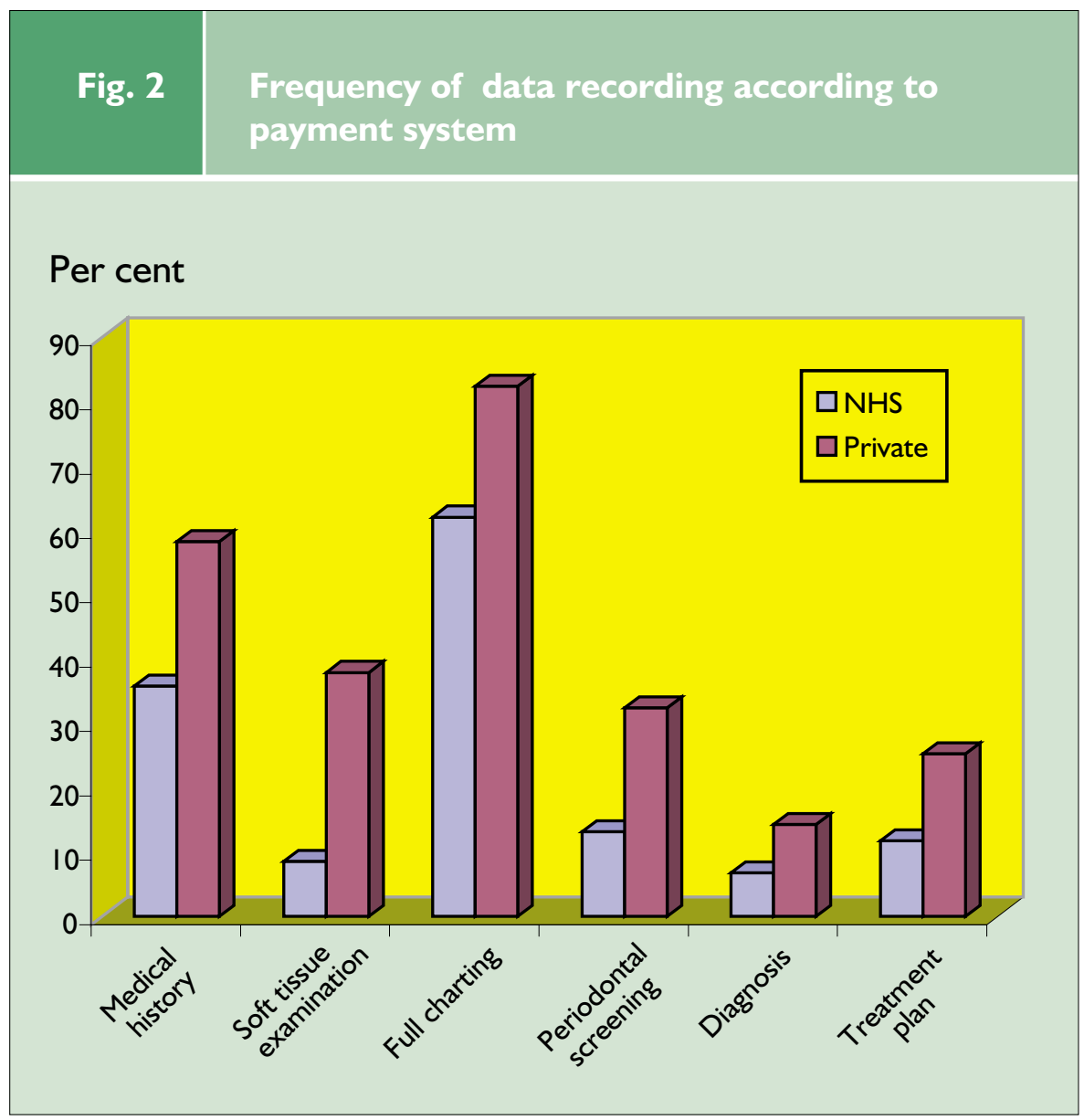

from the USA, ${ }^{14}$ Australia $^{15}$ and Scandinavia ${ }^{16-19}$ all show record keeping that falls below recognised standards, and in line with the findings of this study.

Little difference was found between the notations recorded by male and female dentists, although male dentists recorded information about soft tissue status significantly more often than female dentists. This contrasts to the findings of Helminen et al. who found that female dentists recorded significantly more information about soft tissue status and occlusion than did male dentists, ${ }^{17}$ a finding that the authors were unable to explain. Other papers have found that younger dentists tended to record significantly more information than older dentists, ${ }^{17,18}$ also in contrast to this study. Helminen et al. found that soft tissue status was actually the only item showing this significant relationship, ${ }^{17}$ and postulated that 


\begin{tabular}{|c|c|c|c|c|c|c|c|}
\hline \multirow[t]{2}{*}{ Table 3} & \multicolumn{7}{|c|}{$\begin{array}{l}\text { The presence of record notations according to dentist } \\
\text { experience, dentist gender and patient payment method }\end{array}$} \\
\hline & $\begin{array}{l}\text { Assessed } \\
\text { records }\end{array}$ & $\begin{array}{r}\text { Medical } \\
\text { history }\end{array}$ & $\begin{array}{l}\text { Soft tissue } \\
\text { examination }\end{array}$ & $\begin{array}{c}\text { Full } \\
\text { charting }\end{array}$ & $\begin{array}{l}\text { Periodontal } \\
\text { screening }\end{array}$ & Diagnosis & $\begin{array}{l}\text { Treatment } \\
\text { plan }\end{array}$ \\
\hline $\begin{array}{l}>15 \text { years' } \\
\text { experience }\end{array}$ & 323 & $\begin{array}{c}133 \\
(41.2 \%)\end{array}$ & $\begin{array}{c}74 \\
(22.9 \%)\end{array}$ & $\begin{array}{c}224 \\
(69.3) \%\end{array}$ & $\begin{array}{c}76 \\
(23.5 \%)\end{array}$ & $\begin{array}{c}33 \\
(10.2 \%)\end{array}$ & $\begin{array}{l}64 \\
(19.8 \%)\end{array}$ \\
\hline $\begin{array}{l}\leq 15 \text { years' } \\
\text { experience }\end{array}$ & $|4|$ & $\begin{array}{c}74 \\
(52.5 \%)\end{array}$ & $\begin{array}{c}19 \\
(13.5 \%)\end{array}$ & $\begin{array}{c}101 \\
(71.6 \%)\end{array}$ & $\begin{array}{l}20 \\
(14.2 \%)\end{array}$ & $\begin{array}{c}12 \\
(8.5 \%)\end{array}$ & $\begin{array}{c}15 \\
(10.6 \%)\end{array}$ \\
\hline$P$ & & $0.024 *$ & $0.020 *$ & 0.622 & $0.022 *$ & 0.568 & $0.016 *$ \\
\hline Male & 334 & $\begin{array}{c}156 \\
(46.7 \%)\end{array}$ & $\begin{array}{c}75 \\
(22.5 \%)\end{array}$ & $\begin{array}{c}239 \\
(71.6 \%)\end{array}$ & $\begin{array}{c}76 \\
(22.8 \%)\end{array}$ & $\begin{array}{l}36 \\
(10.8 \%)\end{array}$ & $\begin{array}{l}59 \\
(17.7 \%)\end{array}$ \\
\hline Female & 130 & $\begin{array}{c}5 \mathrm{I} \\
(39.2 \%)\end{array}$ & $\begin{array}{c}18 \\
(13.8 \%)\end{array}$ & $\begin{array}{c}86 \\
(66.2 \%)\end{array}$ & $\begin{array}{l}20 \\
(15.4 \%)\end{array}$ & $\stackrel{9}{(6.9 \%)}$ & $\begin{array}{l}20 \\
(15.4 \%)\end{array}$ \\
\hline$P$ & & 0.146 & $0.037^{*}$ & 0.254 & 0.078 & 0.208 & 0.557 \\
\hline $\mathrm{NHS}$ & 282 & $\begin{array}{c}101 \\
(35.8 \%)\end{array}$ & $\begin{array}{l}24 \\
(8.5 \%)\end{array}$ & $\begin{array}{c}175 \\
(62.1 \%)\end{array}$ & $\begin{array}{l}37 \\
(13.1 \%)\end{array}$ & $\begin{array}{c}19 \\
(6.7 \%)\end{array}$ & (11.7\%) \\
\hline Private & 182 & $\begin{array}{c}106 \\
(58.2 \%)\end{array}$ & $\begin{array}{c}69 \\
(37.9 \%)\end{array}$ & $\begin{array}{c}150 \\
(82.4 \%)\end{array}$ & $\begin{array}{c}59 \\
(32.4 \%)\end{array}$ & $\begin{array}{l}26 \\
(14.3 \%)\end{array}$ & $\begin{array}{c}46 \\
(25.3 \%)\end{array}$ \\
\hline$P$ & & $>0.0001 *$ & $>0.0001 *$ & $>0.0001$ & $>0.0001 *$ & $0.007^{*}$ & $>0.000 I^{*}$ \\
\hline 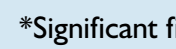 & gs & & & & & & \\
\hline
\end{tabular}

this might be caused by the shift in more recent undergraduate training away from dental examination toward a broader oral health examination. Rasmusson et al. found that the dentist's age has a more significant relationship to the quality of records than the time since qualification. ${ }^{18}$ This, they concluded, might be because of the differing ages of today's dental students, and that older dentists may be less willing to follow rules (sic). The current study found a significant improvement in record quality in dentists of mid-to-late career, compared with those in the early part of their careers. The reasons for the different findings are unclear, but may reflect the effect of sampling bias.

Highly significant differences between records maintained under NHS contracts compared with those under private contract were revealed. The reasons why NHS records were less complete are not clear, but anecdotal feedback from the audited dentists suggests that time constraints produced by need to deliver care as quickly as possible under the NHS regulations leaves little time for accurate record-keeping. If this were the only reason, however, much better quality would be expected of private-contract records, where the fees charged should be appropriate to the time involved in providing treatment and keeping full and contemporaneous records. Private records can hardly be described in this way, when nearly half contained no medical history, and over two thirds had no periodontal screening.

Whether the failure to record essential clinical findings is indicative of a failure to actually carry out the procedures can be questioned. Many dentists do not record the absence of disease, and only note deviations from normality. In medicine, similar levels of omissions from patients' records have been found. Fleming and Lawrence, for example, found that although three-quarters of general practitioners claim to initiate discussion about smoking with basically healthy adults who smoke, less than one-third actually record smoking habits. ${ }^{20}$ Zuckerman et al. found significant under-recording occurred when comparing tape recordings of patient encounters with written records. ${ }^{21}$ Another large study on healthcare provision for children found numerous deficiencies in recording, and found that over half of the physicians felt that their records did not adequately reflect the care that they provided. ${ }^{22}$

Nevertheless, in defining quality dental care, the recording of a patients' history, presenting complaint, diagnosis, treatment plan and execution of treatment must be sufficient to infer the oral health of a patient retrospectively with reasonable certainty. ${ }^{6}$ In this study, for example, where the majority of records contained no periodontal 
diagnostic information, it would be impossible to determine the periodontal health status of these patients.

An additional controversy exists regarding whether focusing on the process of healthcare delivery, or on the resulting outcome, is the best method of assessing the quality of care. Donabedian, the first to describe the concepts of structure, process and outcome as forming the components of healthcare delivery, ${ }^{23}$ recognised that outcomes are the ultimate indicators of quality. ${ }^{24}$ Furthermore, a causative relationship between process and outcome in many aspects of dentistry has yet to be established. ${ }^{25}$ It is possible, therefore, that assuring quality in the process of healthcare may not necessarily assure quality of outcomes for patients. However, the production of practice guidelines carries an inherent assumption that adequate procedures will positively affect the treatment outcome. ${ }^{26}$ Until better systems of outcome assessment are developed, procedural assessment and audit remain the methods of choice for quality assurance in dentistry.

\section{Conclusions}

The quality of record keeping in a group of general practitioners in England and Wales was poor, in keeping with the findings of other worldwide studies. Standards of record keeping were poor for patients funded by both NHS and private contract. Fundamental clinical items that could impact on basic dental care provision were missing from many records.

The lack of a mechanism to monitor such items as record keeping in general practice was noted. More research on a nationwide basis is required to determine the standards that exist in all aspects of primary dental care, irrespective of funding arrangements. This baseline information is at present largely based on rhetoric, and objective evidence must surely be a fundamental requirement before any programme to raise standards can be developed.

The author wishes to thank BUPA Dentalcover Ltd for its co-operation in presenting the findings of this assessment.

1 General Dental Council. Maintaining Standards. Guidance to the Dental Team on Professional and Personal Conduct. London: GDC, 1997.

2 British Dental Association. Ethics in Dentistry Advice Sheet B1. London: British Dental Association, 1995.

3 General Dental Practitioners Association. The Moral and Ethical Responsibilities of Dentists. London, GDPA (under revision).

4 Faculty of General Dental Practitioners (UK). Current Guidelines for General Dental Practice. London: FGDP, January 2000.

5 Medical Defence Union. Guide to good dental practice. London, Medical Defence Union Ltd, 1998.

6 Jerge C R, Orlowski R M. Quality assurance and the dental record. Dent Clin North Am 1985; 29: 483-496.

7 BUPA DentalCover. Quality in Practice. Bournemouth: BUPA DentalCover, 1996.

8 Denplan Excel. A new benchmark of support. Winchester: Denplan Ltd, 1999.

9 Ayton F D, Hill C M, Parfitt H N. The Dental Role in the identification of the victims of the Bradford City football ground fire. Br Dent $\mathrm{J}$ 1985; 159: 262-264.

10 Hill I R, Howell R D, Jarmulowicz M. Identification in the Manchester air disaster. Br Dent J 1988; 165: 445-446.

11 Platt M, Yewe-Dyer M. How accurate is your charting? Dent Update 1995; 22: 374.

12 Martin M V, Butterworth M L, Longman L P. Infective endocarditis and the dental practitioner: a review of 53 cases involving litigation. Br Dent J 1997; 182: 465-468.

13 Marshall K F. Standards and quality assessment in general dental practice. London: $\mathrm{PhD}$ thesis, King's College, 1995.
14 McFall W T, Bader J D, Rozier R G, Ramsey D . Presence of periodontal data in patient records of general practitioners. J Periodont 1988; 59: 445-444.

15 Brown L F, Keily P A, Spencer A J. Hygienist employment and the presence of periodontal notations in general practice records. Aust Dent J 1994; 39: 45-49.

16 Vehkalahti M, Rytomaa I, Helminen S. Assessment of quality of public oral health care on the basis of patient records. Community Dent Oral Epidemiol 1992; 20: 102-105.

17 Helminen S, Vehkalahti M, Murtomaa H, Kekki P, Ketomaki T-M. Quality evaluation of oral health record-keeping for Finnish young adults. Acta Odontol Scand 1998; 56: 288-292.

18 Rasmusson L, Rene N, Dahlbom U, Borrman $\mathrm{H}$. Quality evaluation of patient records in Swedish dental care. Swed Dent J 1994; 18: 233-241.

19 Helminen S E, Vehkalahti M, Kerosuo E, Murtomaa H. Quality evaluation of process of root canal treatments performed on young adults in Finnish public oral health service. J Dent 2000; 28: 227-232.

20 Fleming D M, Lawrence M S T A. An evaluation of recorded information about preventive measures in 38 practices. JR Coll Gen Pract 1981; 31: 615-620.

21 Zuckerman A E, Starfield B, Hochreiter C et al. Validating the content of pediatric outpatient medical records by tape-recording doctorpatient encounters. Pediatrics 1975; 56: 407-411.

22 Osbourne C E, Thompson N H. Criteria for evaluation of ambulatory child healthcare by chart audit-development and testing of a methodology. Pediatrics 1975; 56: Supp Part 2: 625-692.

23 Donabedian A. Evaluating the quality of medical care. Millbank Memorial Fund Q 1966; 44: 166-203.

24 Donabedian A. The definition of quality: a conceptual exploration. In Explorations in Quality Assessment and Monitoring. Volume I: The definition of quality and approaches to its assessment. Michigan: Health Administration Press, Ann Arbor, 1980.

25 Antczak-Bouckoms A. Quality and effectiveness issues related to oral health. Med Care 1995; 53(suppl): 123-142.

26 Bader J D, Shugars D A. Variation, treatment outcomes and practice guidelines in dental practice. J Dent Educ 1995; 59: 61-95. 